\title{
Comparative Histologic Analysis of \\ Coronally Advanced Flap With and Without Collagen Membrane for Root Coverage
}

Eun-Ju Lee, ${ }^{*}$ Stephen J. Meraw,${ }^{\dagger}$ Tae-Ju Oh,${ }^{\dagger}$ William V. Giannobile, ${ }^{\dagger}$ and Hom-Lay Wang ${ }^{\dagger}$

Background: Guided tissue regeneration (GTR)-based root coverage has been utilized to correct gingival recession defects with promising results. However, limited histologic information is available. Therefore, the aims of this study were to clinically and histologically evaluate the efficacy of GTR-based root coverage using collagen membrane (GTRC) and to compare the healing response to that of coronally advanced flaps (CAF).

Methods: Standardized gingival recession defects were surgically created on the labial surfaces of the maxillary cuspids of 8 mongrel dogs. Plaque was allowed to accumulate for 8 weeks to develop a plaque-infected recession defect. Full-mouth scaling and root planing was then performed coincident with 4 weeks of oral hygiene. Defects were randomly assigned to receive either GTRC or CAF surgery. Four dogs each were sacrificed at 4 and 16 weeks post-treatment. Clinical measurements included: percent root coverage, the amount of keratinized gingiva (KG), and probing depth (PD). Sulcular depth, junctional epithelium and connective tissue attachment, new cementum formation, and new bone formation were evaluated histomorphometrically.

Results: Clinically, both treatments (CAF and GTRC) achieved statistically significant $(P<0.05)$ root coverage compared to baseline. KG was significantly increased in CAF-treated sites at 16 weeks, while no significant differences were found for other clinical parameters between treatments. Histometrically, GTRC showed a statistically significant increase of new attachment and newly formed connective tissue when compared to CAF at 16 weeks.

Conclusion: Within the limits of this preclinical study, both GTRC and CAF can be successfully used for the treatment of gingival recession defects. J Periodontol 2002;73:779-788.

\section{KEY WORDS}

Collagen/therapeutic use; comparison studies; gingival recession/surgery; gingival recession/therapy; membranes, barrier; membranes, bioabsorbable; guided tissue regeneration; surgical flaps; wound healing.

\footnotetext{
* Previously, Department of Periodontics/Prevention/Geriatrics, School of Dentistry, University of Michigan, Ann Arbor, MI; currently, private practice, Seoul, Korea.

$\dagger$ Department of Periodontics/Prevention/Geriatrics, School of Dentistry, University of Michigan.
}

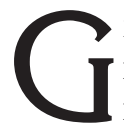
ingival recession (soft tissue or marginal) is defined as displacement of the gingival margin apical to the cemento-enamel junction (CEJ). ${ }^{1}$ Common causes of recession include: traumatic tooth brushing technique, periodontal disease ${ }^{2}$ high muscle attachment and frenal pull, tooth position, ${ }^{3}$ alveolar bone dehiscence, ${ }^{2}$ and iatrogenic factors. ${ }^{4}$ Consequences of gingival recession include problems associated with esthetics, root sensitivity, and/or root caries. ${ }^{2}$

A variety of periodontal plastic procedures have been developed and have shown promising results in correcting gingival recession defects. ${ }^{5-7}$ Traditional approaches, such as the coronally advanced flap (CAF) and its modifications have been used in periodontics for many years. ${ }^{6,8}$ CAF offers several advantages compared to other traditional root coverage procedures, which include no need for a donor site and a better color and contour match. However, CAF is often limited by the height and thickness of the gingiva apical to the recession and can only be applied to recession with an adequate width and thickness of keratinized gingiva (KG) tissue. In addition, recession treated with traditional approaches such as the lateral sliding flap mainly healed by a long junctional epithelium with a limited amount of bone and cementum formation. ${ }^{9}$ GTR-based root coverage has emerged as an alternative treatment because it may not only achieve similar clinical results to those of traditional root coverage procedures, but also demon- 
strate histologically new attachment formation. ${ }^{10-13}$ Root coverage using GTR offers advantages such as no need for donor tissue, readily commercial available materials, and esthetic outcomes as comparable to traditional approaches. ${ }^{14}$

Tinti et al. ${ }^{12}$ used non-absorbable expanded polytetrafluoroethylene (ePTFE) to treat human buccal recession in 12 patients, and obtained average recession reduction of $2.50 \mathrm{~mm}$ and attachment gain of $2.84 \mathrm{~mm}$. Cortellini et al. ${ }^{11,15}$ further confirmed that sites receiving GTR demonstrated formation of new bone, cementum, and periodontal ligament. Nonetheless, GTR-based root coverage utilizing non-absorbable membranes has several drawbacks, including membrane removal and high membrane exposure rates. ${ }^{16}$ To overcome these, bioabsorbable membranes, such as collagen and polylactide or polyglycolide, were developed and have achieved similar results to those obtained by non-absorbable barriers. ${ }^{17,18}$

Collagen, a major component of the periodontium, has shown promising results for the treatment of gingival recession. ${ }^{18}$ The rationale of using collagen membranes for root coverage include: 1) proven barrier function; ${ }^{19}$ 2) bioabsorbable; ${ }^{20} 3$ ) chemotactic function; ${ }^{21}$ and 4) hemostatic properties. ${ }^{22}$ Wang et al. ${ }^{14}$ compared GTRC to subepithelial connective tissue graft, and reported similar enhancement of root coverage. Ozcan et al. ${ }^{23}$ found similar amounts of root coverage between GTRC and CAF. However, GTRC-treated sites revealed clinical attachment gain as compared to CAF.

Most of these studies have reported clinical outcomes, and limited information is available regarding the regenerated tissue at the microscopic level. Therefore, the aims of this study were: 1) to clinically and histologically evaluate the efficacy of GTRC and 2) to compare healing response between GTRC and CAF.

\section{MATERIALS AND METHODS}

This study was approved by University Committee on Use and Care of Animals at University of Michigan. Eight 2- to 3-year-old healthy male mongrel dogs were used in this study. Using a computer-generated randomization program, the animals were divided into 2 groups of 4 each. Using a split-mouth design, 2 maxillary cuspids in each animal were randomly assigned by a coin-flip to receive either CAF or GTRC. The experimental timeline is shown in Figure 1. Procedures were performed in a standard sterile operating room fashion under general anesthesia as follows: intramuscular injections of butorphanol $(0.2 \mathrm{mg} / \mathrm{kg})$, acepromazine $(0.05 \mathrm{mg} / \mathrm{kg})$, and glycopyrolate $(0.01$ $\mathrm{mg} / \mathrm{kg}$ ) were given to the animals 20 to 30 minutes prior to surgery. An IV catheter was placed into the cephalic vein, and anesthesia was induced with 12 $\mathrm{mg} / \mathrm{kg}$ of Na thiopental intravenously. In addition, an endotracheal tube was placed to ensure a patent airway and for administration of $1 \%$ to $2 \%$ of isoflurane mixed with 22 to $44 \mathrm{ml} / \mathrm{kg} /$ minute of oxygen during the surgery. Anesthesia depth was monitored by heart rate, respiration rate, jaw tone, corneal reflex, and foot withdrawal reflex. Additionally, IV fluids at a rate of 10 $\mathrm{ml} / \mathrm{kg} /$ hour were administrated. For local anesthesia and hemostasis of the surgical areas, $2 \%$ xylocaine with 1:100,000 epinephrine was employed. To prevent postsurgical infection, antibiotics (amoxicillin $500 \mathrm{mg}$ PO BID) were administered for 2 weeks following surgery. In addition, a long acting opioid, buprenorphine $(0.015 \mathrm{mg} / \mathrm{kg}$, IM) was given to the animals immediately after surgery and postsurgically every 12 hours for up to 96 hours as needed. After 2 weeks of pretreatment adjustment, all animals received full mouth scaling using ultrasonic and hand instrumentation. Then, the standardized labial gingival recession defects ( $5 \mathrm{~mm}$ from CEJ and $5 \mathrm{~mm}$ mesial to distal) were surgically created on both maxillary cupids by using chisels and sterile water-cooled carbide and diamond burs. The root surface was then hand instrumented for cementum removal. No oral hygiene measures were employed for 8 weeks to facilitate plaque accumulation. After this period, all animals received fullmouth scaling and root planing. Areas were maintained with oral hygiene, daily tooth brushing and application of $0.12 \%$ chlorhexidine by cotton swab for 4 weeks 
to the surgical treatment area. Clinical baseline data were then recorded using the UNC-15 probe $^{\ddagger}$ by one calibrated examiner with gentle manual probing, with care to avoid the exact midfacial point where histologic sections would be made. Measurements were rounded up to the nearest millimeter for the following: 1) clinical gingival recession (GR): measured from CEJ to gingival margin; 2) width of KG: recorded from gingival margin to mucogingival junction; and 3) PD: assessed from free gingival margin to the depth of probing depth.

After adequate anesthesia, defects were restandardized to specified dimensions ( $5 \mathrm{~mm}$ from CEJ and 5 $\mathrm{mm}$ mesial to distal) with slight gingivectomy due to minimal overgrowth during initial healing. A flap of full- and partial-thickness with oblique vertical incisions beyond the mucogingival junction was made. The root surface was thoroughly scaled and root planed. A coronal reference notch was marked along the CEJ, and an apical notch was made at the level of alveolar crest using a $1 / 2$ round bur. The distance between 2 notches was standardized to $7 \mathrm{~mm}$ using the UNC-15 probe. ${ }^{\ddagger}$ Sites were then randomly assigned by flipping a coin to receive CAF at one site and GTRC at the contralateral site. The flap and tooth preparation was the same at all sites except that in the GTRC group, a collagen membrane (bovine type I collagen§) was used in addition to the CAF. The membranes were trimmed and extended beyond defects 3 to $4 \mathrm{~mm}$ all the way around. The membrane was then secured to the tooth via a bioabsorbable 4-0 suturell with a sling technique. The flap was repositioned and sutured at a level coronal to the pretreatment position, attempting to completely cover the defect and/or barrier membrane. No periodontal dressings were used.

\section{Specimen Retrieval}

After 4 and 16 weeks of healing, clinical parameters were recorded avoiding the exact midfacial aspect where histologic sections were to be made. Animals were then euthanized with an overdose of pentobarbital. Block sections of the cuspid and surrounding tissue including bone were obtained. Blocks were immediately fixed and stored in $4 \%$ paraformaldehyde, and subsequently dehydrated in step gradients of alcohol, infiltrated, and embedded in methyl methacrylate by routine histological methods. Serial sections of 4 to 5 $\mu \mathrm{m}$ were made in the bucco-lingual plane at $0.1 \mathrm{~mm}$ intervals and stained by toluidine blue. Three representative sections per specimen located at the central region of the gingival recession defects were made, which identified both coronal and apical reference notches. Histologic and histomorphometric analyses were performed using a microscope fitted with a computer programmed with measurement software. " The measurements of 3 sections per each site were aver-

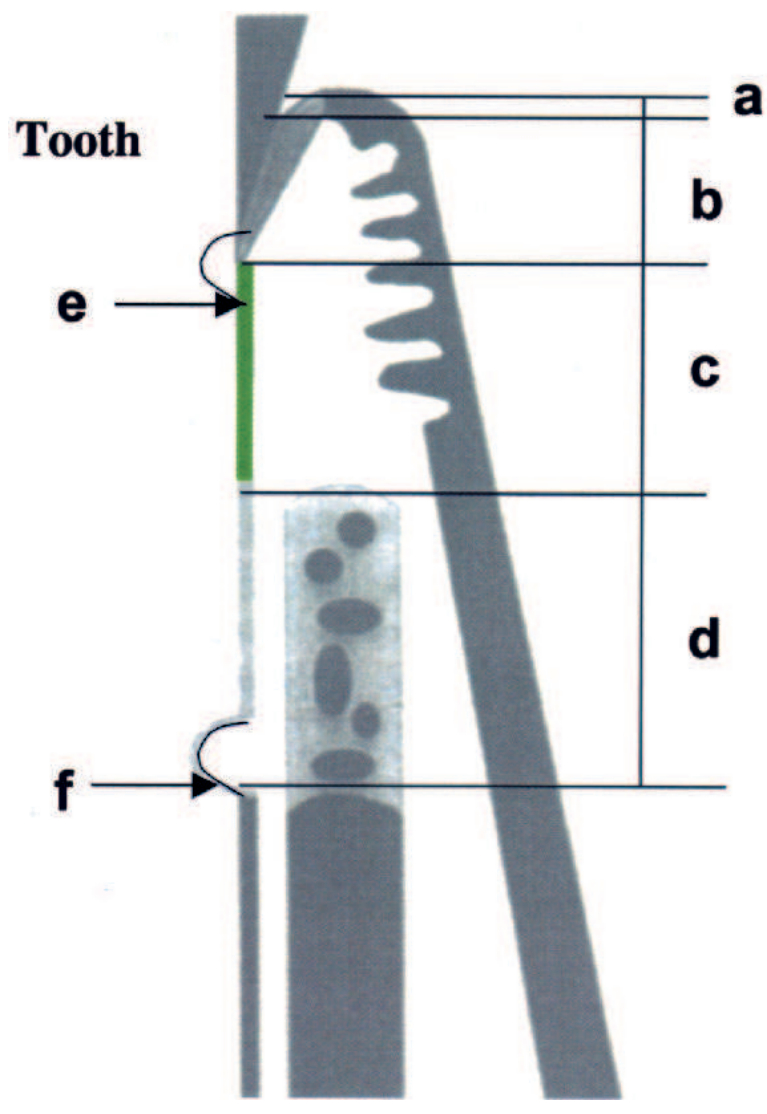

Figure 2.

Histomorphometric parameters. a) sulcular epithelium; b) junctional epithelium; c) connective tissue attachment; d) new bone formation; e) coronal notch; and f) apical notch.

aged and used for histomorphometric analyses. Data were recorded by a masked examiner unaware of the treatment variable. The intra-examiner calibration error was revealed to be less than $5 \%$ for all parameters assessed in the study. Histologic observations included the presence or absence of inflammatory infiltrate and ankylotic bone to the tooth surface. Figure 2 shows the histomorphometric parameters analyzed: sulcular depth, length of junctional epithelium (JE), connective tissue attachment (CTA), height of new bone, area of new bone, and length of new cementum.

\section{Statistical Analysis}

Data were presented as mean and standard deviation (SD). A paired $t$ test was utilized to analyze treatment effect (between treatments) as well as time effect (baseline versus 4 or 16 weeks) within and between groups, both clinically and histologically. Significance was reported at the $95 \%$ confidence level $(P<0.05)$.

† Hu-Friedy Mfg. Co. Inc., Chicago, IL.

$\S$ BioMend Regular, Sulzer Dental, Inc., Carlsbad, CA.

$\|$ Vicryl, Ethicon Inc., Johnson E Johnson Company, Somerville, NJ.

II Image-Pro Plus, The Imaging Express, Media Cybernetics, Silver Spring, MD. 


\section{RESULTS}

No clinical adverse effects were observed for either treatment. There was no collagen membrane exposure noted.

\section{Clinical Measurements}

Table 1 lists clinical results obtained from this study. There were no statistical differences in GR, KG, and PD at baseline.

\section{Four-Week Results}

At 4 weeks, both treatment procedures resulted in statistically significant reduction $(P<0.05)$ of $\mathrm{GR}$ when compared to baseline. This translates to $92 \%$ and $72 \%$ of root coverage for CAF and GTRC, respectively (Table 1). However, no statistically significant difference was noted between treatments. It was noted that one site receiving GTRC obtained only $11 \%$ root coverage (Fig. 3). If this site is considered a treatment failure and deleted from the analysis, the average percent of root coverage for GTRC increases to $92 \%$.

Table I.

Comparison of Clinical Parameters Between CAF and GTRC at 4 and 16 Weeks Following Surgery

\begin{tabular}{|c|c|c|}
\hline Clinical Parameter & $\begin{array}{c}\text { CAF } \\
(N=4)\end{array}$ & $\begin{array}{c}\text { GTRC } \\
(N=4)\end{array}$ \\
\hline \multicolumn{3}{|l|}{ Gingival recession (\%) } \\
\hline Baseline & $-4.5 \pm 0.0$ & $-4.4 \pm 0.2$ \\
\hline 4 weeks & $-0.4 \pm 0.2 *$ & $-1.3 \pm 2.8 *$ \\
\hline$\%$ root coverage & $91.7 \pm 16.6$ & $72.2 \pm 61.2$ \\
\hline Baseline & $-4.3 \pm 0.2$ & $-4.5 \pm 0.4$ \\
\hline 16 weeks & $-1.9 \pm 1.4^{*}$ & $-1.5 \pm 2.6 *$ \\
\hline$\%$ root coverage & $55.8 \pm 29.8$ & $66.3 \pm 56.8$ \\
\hline \multicolumn{3}{|c|}{ Keratinized gingiva (mm) } \\
\hline Baseline & $3.8 \pm 3.0$ & $3.9 \pm 3.0$ \\
\hline 4 weeks & $5.0 \pm 4.0$ & $4.3 \pm 3.8$ \\
\hline Gain of KG & $1.2 \pm 1.4$ & $0.4 \pm 1.6$ \\
\hline Baseline & $2.0 \pm 1.2$ & $2.7 \pm 2.0$ \\
\hline 16 weeks & $4.1 \pm 1.2 *$ & $3.6 \pm 0.8$ \\
\hline Gain of KG & $2.1 \pm 1.0 *$ & $0.9 \pm 2.2$ \\
\hline \multicolumn{3}{|l|}{ Probing depth (mm) } \\
\hline Baseline & $1.5 \pm 0.0$ & $1.5 \pm 0.0$ \\
\hline 4 weeks & $4.3 \pm 1.6^{*}$ & $3.8 \pm 1.8 *$ \\
\hline Change in PD & $2.8 \pm 1.6$ & $2.3 \pm 1.8$ \\
\hline Baseline & $1.5 \pm 0.0$ & $1.5 \pm 0.0$ \\
\hline 16 weeks & $3.4 \pm 1.6^{*}$ & $2.8 \pm 0.8 *$ \\
\hline Change in PD & $1.9 \pm 1.6$ & $1.3 \pm 0.8$ \\
\hline
\end{tabular}

Values are expressed as mean \pm standard deviation $(\mathrm{mm})$.

* Significantly different from baseline within each treatment (paired $t$ test, $P<0.05)$.
Both groups showed a gain of $\mathrm{KG}$ when compared to baseline, $1.2 \mathrm{~mm}$ (from 3.8 to $5.0 \mathrm{~mm}$ ) for CAF and $0.4 \mathrm{~mm}$ (from 3.9 to $4.3 \mathrm{~mm}$ ) for GTRC. No statistically significant difference was found between treatments and between baseline and 4 weeks.

\section{Sixteen-Week Results}

At 16 weeks, both CAF and GTRC displayed significant reduction $(P<0.05)$ of $\mathrm{GR}$ when compared to baseline. The average root coverage for CAF and GTRC was $56 \%$ and $66 \%$, respectively. Again, no statistically significant difference was found between treatments. Figure 3 shows the percentage root coverage and the corresponding number of sites. Three sites (2 GTRC and 1 CAF) had root coverage $\leq 60 \%$. The amount of root coverage was decreased in CAF (from $92 \%$ at 4 weeks to $56 \%$ at 16 weeks), while remaining relatively stable in GTRC sites (from $72 \%$ at 4 weeks to $66 \%$ at 16 weeks).

At 16 weeks, CAF-treated sites demonstrated a statistically significant increase $(2.1 \mathrm{~mm})$ in $\mathrm{KG}$ when compared to baseline, while there was only a small (0.9 mm) gain of KG in GTRC-treated sites. Again, no statistically significant difference was found between CAF and GTRC.

An increase in PD was noted at 16 weeks: $1.9 \mathrm{~mm}$ and $1.3 \mathrm{~mm}$ for CAF and GTRC, respectively. In addition, no statistically significant difference was found between treatments.

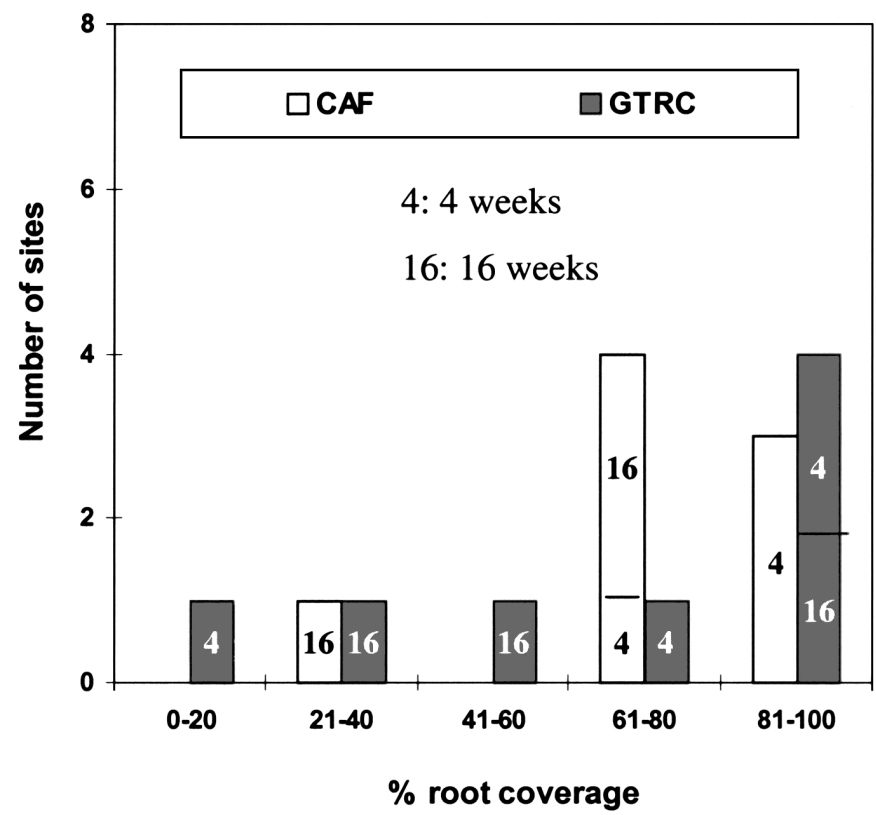

Figure 3.

Root coverage expressed as a percentage of the total defect and the corresponding number of sites for each treatment at 4 and 16 weeks. $\%$ root coverage $=$ (original recession depth - recession depth after treatment)/original recession depth $\times 100$. 


\section{Histologic Observations}

New connective tissue and new bone formation was noted in both treatments at 4 weeks; however, the amount was minimal (Figs. 4 and 5). No new cementum formation was identified at this time. In some GTRC sites, remnants of membrane were found, and they were surrounded by numerous inflammatory cells (Fig. 5).

At 16 weeks, new bone, new cementum, and new connective tissue formation was evident in both treatments (Figs. 6 and 7). GTRC-treated sites demonstrated higher frequency of these findings than CAF.

\section{Histomorphometric Analysis}

Table 2 lists histomorphometric results for both treatments. At 4 weeks, similar histological healing was
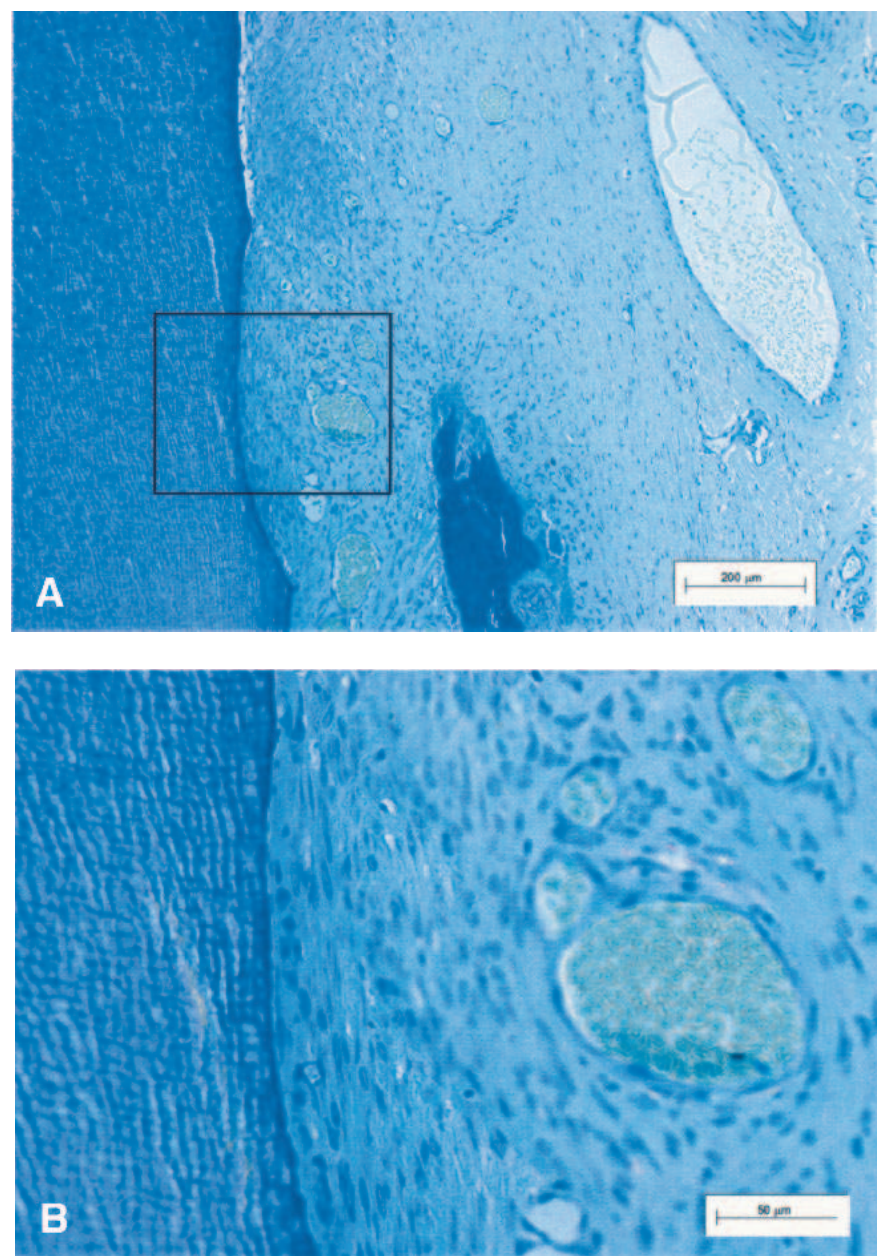

\section{Figure 4.}

Healing response at 4 weeks following CAF. $\boldsymbol{A}$. New bone formation in the apical notch can be observed (original magnification $\times 10$, toluidine blue stain). B. Higher magnification view of the area in A. This area is filled with connective tissue with inflammatory cell infiltration devoid of new cementum formation (original magnification $\times 40$, toluidine blue stain). noted between CAF and GTRC. Statistically, no difference was noted between treatments. New bone formation was minimal for both treatment groups and no cementogenesis was found.

At 16 weeks, GTRC showed statistically significantly higher amounts of connective tissue $(P<0.05)$ compared to CAF. In addition, GTRC showed a trend of more new bone and new cementum formation than CAF-treated sites. However, this difference was not statistically significant. For new connective tissue formation, CAF-sites decreased significantly from 2.48 $\mathrm{mm}$ (4 weeks) to $1.10 \mathrm{~mm}$ (16 weeks), while the change of connective tissue was minimal in GTRC (from 2.65 to $2.45 \mathrm{~mm}$ ). The length of JE was increased in the CAF group, whereas it was reduced in GTRC-treated teeth from 4 weeks to 16 weeks.
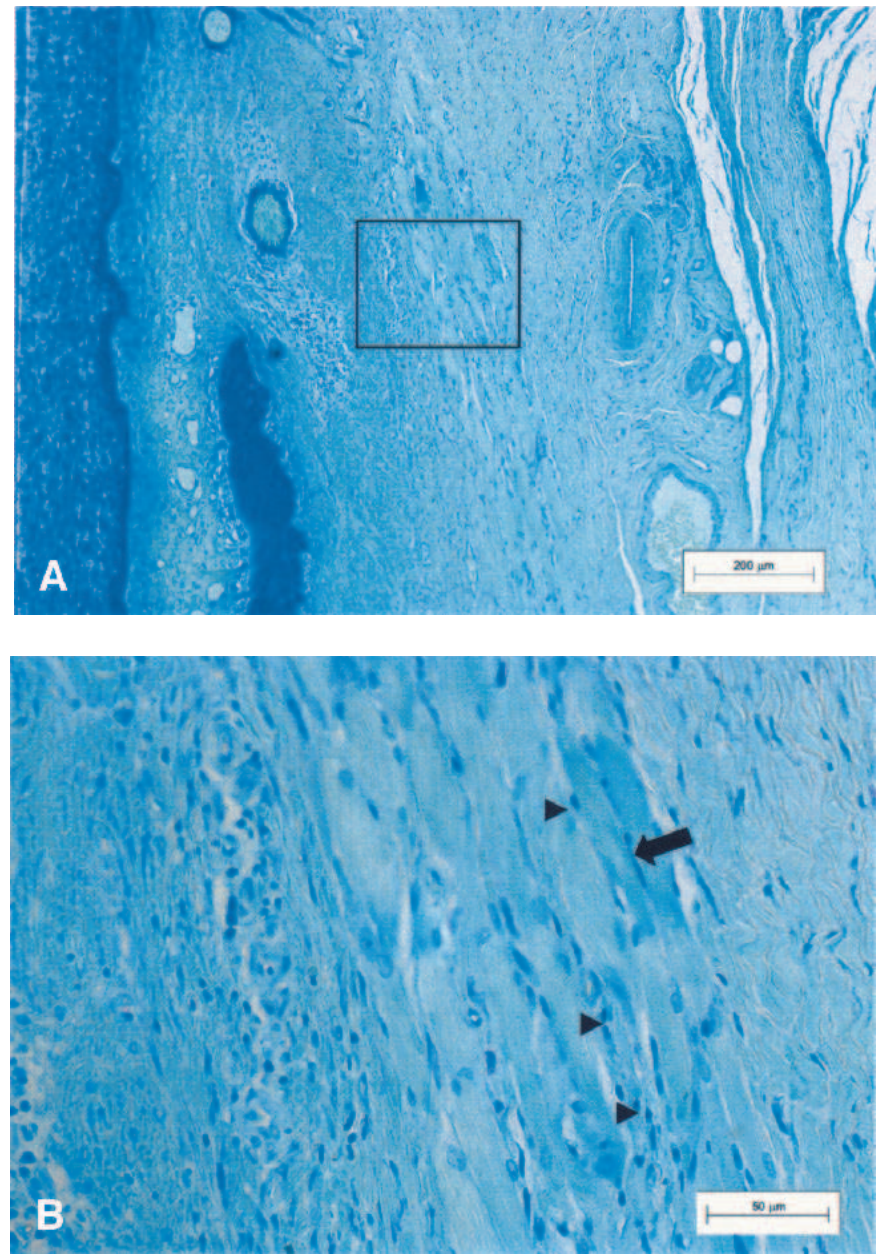

Figure 5.

Healing response at 4 weeks following GTRC. $\boldsymbol{A}$. Reveals new bone formation along the root surface coronal to the apical notch. No new cementum formation can be observed (original magnification $\times 10$, toluidine blue stain). B. Higher magnification view of the area in A, demonstrating remnants of the collagen membrane (arrow) with inflammatory cells infiltration (arrowheads) (original magnification $\times 40$, toluidine blue stain). 

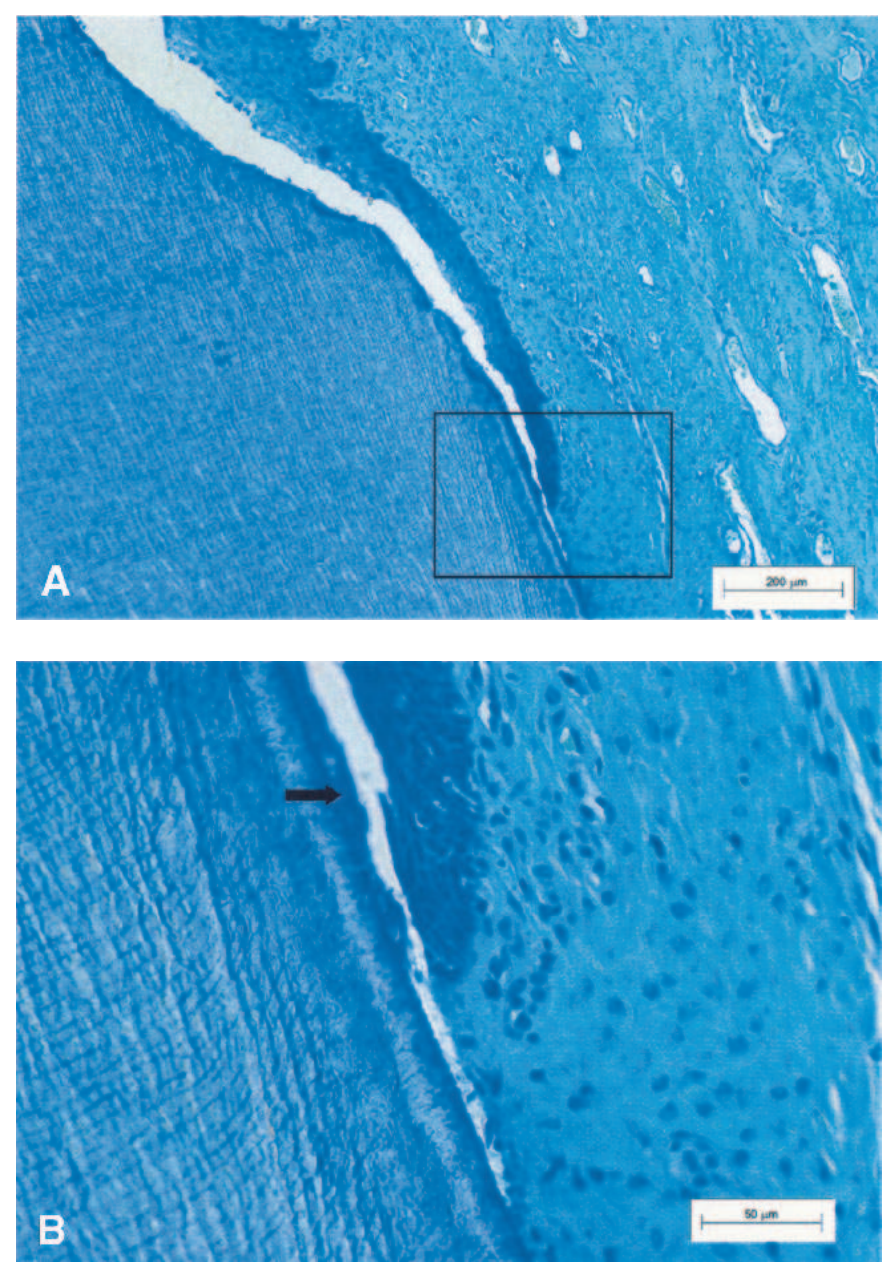

Figure 6.

Healing response at 16 weeks following CAF. A. Note a long junctional epithelium below the apical reference notch. No new bone formation can be seen (original magnification $\times 10$, toluidine blue stain). B. A detailed view of junctional epithelium of the area in A. Apical downgrowth of the epithelium and presence of cementum (arrow) are clearly visible (original magnification $\times 40$, toluidine blue stain).

There was no significant change in the other parameters evaluated (new bone height, new bone area, and new cementum) when both treatment- and timeeffects were examined.

\section{DISCUSSION}

The present study was designed to investigate histologic and histometric differences between CAF and GTRC for the treatment of gingival recession defects. Previous studies have demonstrated several limitations in the use of CAF, including the height and thickness of the gingiva apical to the recession, the presence or absence of keratinized gingiva, and limited/non-ideal regeneration of lost periodontium. ${ }^{24}$ Most of the traditional root coverage procedures including CAF have been reported to heal by long junctional epithelium with minimal amount of new attachment. ${ }^{25,26}$ On the
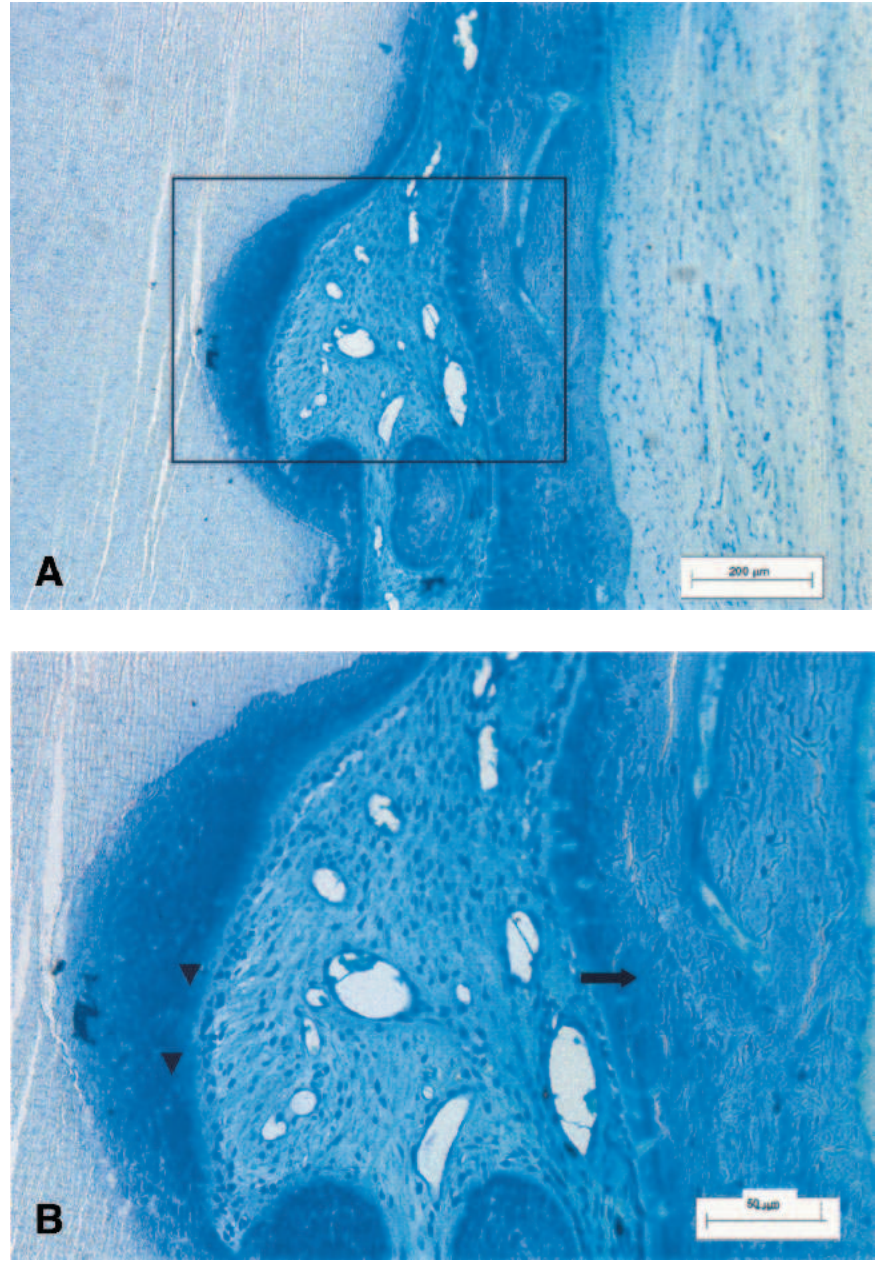

Figure 7.

Healing response at 16 weeks following GTRC A. New bone and cementum formation can be observed above the apical reference notch (original magnification $\times 10$, toluidine blue stain). B. Higher magnification view of the area in A. Arrow and arrow heads represent new bone and new cementum formation, respectively. The area between bone and cementum is filled with richly vascularized connective tissue (original magnification $\times 40$, toluidine blue stain).

other hand, GTR-based root coverage procedures have been shown to result in new attachment formation while producing comparable clinical outcomes to those obtained by traditional approaches. ${ }^{10,12,13,27}$ In particular, bioabsorbable collagen membrane has gained popularity due to its properties. It has been demonstrated that collagen stimulates platelet attachment, enhances fibrin linkage, and is chemotactic for fibroblasts. ${ }^{21}$ It also inhibits apical migration of epithelium, ${ }^{19}$ stabilizes the wound, and augments tissue thickness via enzymatic degradation. ${ }^{20}$ These characteristics have made collagen an attractive material for GTR-based root coverage. The rationale of this preclinical in vivo study was to demonstrate the nature of healing response in created recession defects between GTRC and CAF and to assess histologic, histometric, and clinical parameters. 
Table 2.

\section{Histomorphometric Comparison Between CAF and GTRC at 4 and 16 Weeks Postsurgery}

\begin{tabular}{|c|c|c|}
\hline Histomorphometric Parameters & $\begin{array}{c}\text { CAF } \\
(n=4)\end{array}$ & $\begin{array}{c}\text { GTRC } \\
(n=4)\end{array}$ \\
\hline \multicolumn{3}{|l|}{ Sulcus depth (mm) } \\
\hline 4 weeks & $1.30 \pm 0.32$ & $1.07 \pm 0.18$ \\
\hline 16 weeks & $0.93 \pm 0.40$ & $1.15 \pm 1.20$ \\
\hline \multicolumn{3}{|l|}{ Junctional epithelium (mm) } \\
\hline 4 weeks & $0.63 \pm 0.22$ & $1.48 \pm 1.92$ \\
\hline 16 weeks & $1.08 \pm 0.56$ & $1.22 \pm 0.70$ \\
\hline \multicolumn{3}{|l|}{ Connective tissue (mm) } \\
\hline 4 weeks & $2.48 \pm 1.80$ & $2.65 \pm 2.60$ \\
\hline 16 weeks & $1.10 \pm 1.38$ & $2.45 \pm 1.74 *$ \\
\hline \multicolumn{3}{|l|}{ New bone height (mm) } \\
\hline 4 weeks & $0.62 \pm 0.70$ & $0.21 \pm 0.62$ \\
\hline 16 weeks & $0.54 \pm 1.62$ & $1.68 \pm 1.70$ \\
\hline \multicolumn{3}{|l|}{ New bone area $\left(\mathrm{mm}^{2}\right)$} \\
\hline 4 weeks & $0.50 \pm 0.92$ & $0.01 \pm 0.04$ \\
\hline 16 weeks & $0.09 \pm 0.28$ & $0.34 \pm 0.34$ \\
\hline \multicolumn{3}{|l|}{ New cementum (mm) } \\
\hline 4 weeks & $0.00 \pm 0.00$ & $0.00 \pm 0.00$ \\
\hline 16 weeks & $0.30 \pm 0.90$ & $0.41 \pm 1.22$ \\
\hline
\end{tabular}

Values are expressed as mean \pm standard deviation.

* Significantly different from CAF-treated sites ( $t$ test, $P<0.05$ ).

Results from this animal study indicated that root coverage utilizing a bioabsorbable collagen membrane resulted in higher amount of connective tissue, and a trend toward higher amounts of bone and cementum when compared to traditional CAF. This may be explained by the fact that collagen membranes can act as a GTR barrier excluding epithelial cells and allow undifferentiated mesenchymal cells to repopulate the space and to promote tissue regeneration. In addition, collagen membrane not only can increase tissue thickness via membrane integration with the flap but also protect initial attachment gain. ${ }^{27}$ Other properties such as hemostatic and chemotactic properties may also play an important role in this type of treatment. This is in agreement with Cortellini et al., ${ }^{10}$ who reported significantly higher amounts of new connective tissue with GTR than with a laterally positioned pedicle graft for the treatment of gingival recession defects in dogs. Similar results were also reported by Weng et al. ${ }^{28}$ In this study, the sites treated with GTR procedure resulted in higher amounts of new bone formation than in the connective tissue graft group; however, they were not statistically significant. This is somehow contradictory to the results reported by Casati et al. ${ }^{29}$ They compared bioabsorbable polylactic acid membranes to
CAF for the treatment of gingival recession. No statistical differences were found between the 2 treatments in any of the evaluated histological parameters. The different results observed between the Casati et al. study and ours could be explained by the different membranes used: a hydrophobic barrier material made from polylactic acid combined with a citric acid ester versus collagen. In a 14-week human biopsy specimen, Tatakis and Trombelli ${ }^{30}$ showed remnants of membrane along with a typical foreign body reaction, which were surrounded with numerous multinucleated giant cells and foamy macrophages. Hence, it could be speculated that the foreign body reaction and its byproducts during degradation might have affected the outcomes. However, the small sample size in both studies may limit accurate comparisons.

CAF had a significantly higher amount of new attachment formation at 4 weeks than 16 weeks (Table 2 ). This implies that the initial gain of attachment was due to advancement of flap, and this may eventually disappear as demonstrated in the present study. On the other hand, this phenomenon was not seen in GTRC, where the gain of attachment increased over time, however, not significantly. This may be attributed to membrane ability in creating space for PDL/bone cells to promote tissue regeneration. A similar observation was also reported by da Silva Pereira et al., ${ }^{31}$ who reported a superior length of new bone and cementum in sites treated by GTR with bioabsorbable polylactic acid when compared to open flap debridement for the treatment of dehiscence-type gingival recession defects.

In addition, the degradation process of collagen membrane may explain why new attachment formation was less at 4 weeks than at 16 weeks. Since the collagen membrane absorption requires foreign body reaction, which may, in turn, cause initial delayed wound healing. A similar phenomenon was reported by Cortellini et al., ${ }^{10}$ who thought that the membrane might act as a foreign body and a plaque-retentive device, thus causing osteoclastic activation during the early healing phase. This is further supported by our histological observation, where numerous multinucleated cells and neutrophils were commonly found in the connective tissue along the surface of the residual membrane observed at 4 weeks. With a longer healing period, the space occupied by membrane and multinucleated/leukocyte cells was slowly replaced by new attachment consisting of connective tissue, bone, and cementum. Hence, a longer healing time may be needed for GTRC to achieve optimal results. This confirms our clinical observations. CAF-treated sites had higher amounts of root coverage at 4 weeks but it was reduced at 16 weeks (from $92 \%$ to $56 \%$ ). On the contrary, the amounts of root coverage in GTRC remained stable over time (from $72 \%$ to $66 \%$ ). 
Clinically, in the present study, a significant reduction of gingival recession was noted in both treatments at 4 and 16 weeks. CAF resulted in root coverage ranging from $56 \%$ to $92 \%$. This is in agreement with previous human clinical trials, ${ }^{32,33}$ where more than $95 \%$ of root coverage was reported. On the other hand, the mean root coverage of GTRC-treated sites ranged from $66 \%$ to $72 \%$. This compares well with a previous human clinical trial, ${ }^{14}$ in which the same collagen membrane was used to treat gingival recession in 16 patients, and $73 \%$ root coverage was reported. The amount of root coverage reported in this study is somehow less than others reported in the literature. ${ }^{12,16}$ The average $56 \%$ to $66 \%$ of root coverage after 4 months in this study is particularly notable. This might have been in part due to 2 outliers, 1 GTRC and 1 CAF site, which showed $\leq 40 \%$ of root coverage (Fig. 3 ). The unfavorable outcomes found in the outliers could be considered failures to root coverage (25\% failure rate in each group). It suggests that root coverage procedures are technique sensitive, and success of root coverage may be influenced by the condition of surgical sites, such as soft tissue thickness. ${ }^{34}$ In addition, differences of root coverage outcomes between studies may be partly explained by type of membrane used (polylactide versus collagen), size of defects, observation period length, and measuring methods employed. Also the small sample size may add more variation in the interpretation of the results. Hence, the ability to directly compare the percent of root coverage between this study and those previous clinical human trials is limited.

Several factors may influence clinical outcomes obtained by GTR. These include types of membrane, the shape or size of defect, tissue thickness, space making, and the presence or absence of membrane exposure.

The collagen membranes used in our study are composed of bovine type I collagen, heavily cross-linked with a retention time of 6 to 7 weeks. This retention time is considered to be adequate for tissue regeneration in infrabony ${ }^{35}$ and furcation ${ }^{19}$ defects. However, the longevity of collagen membranes, utilized for the treatment of gingival recession, has not been determined. Future study in this area is needed.

The size of defect has been shown to influence the outcome of GTR-based root coverage procedures. ${ }^{36,37}$ Pini Prato et al. ${ }^{36}$ reported that GTR produced a greater amount of root coverage when the recession was $\geq 4.98$ $\mathrm{mm}$. In our study, the defect was created deep enough to obtain benefit from GTR-based root coverage (5 $\mathrm{mm}$ from (EJ) at pretreatment phase. Nonetheless the overgrown gingival tissue had to be excised at baseline to standardize the defect size, resulting in significant reduction in PD at baseline and thus significant discrepancy in PD between baseline and 4 or 16 weeks.
It was suggested that the increase in PD during healing resulted from reformation of sulcular epithelium, junctional epithelium, and some part of connective tissue attachment. At 16 weeks, GTRC had shallower PD than CAF, corresponding to more histologic gain of new attachment in sites treated with GTRC than CAF.

Exposure of membranes has been a common complication of GTR-based root coverage. ${ }^{38}$ Postoperative membrane exposure has been shown negatively related to the amount of root coverage achieved. ${ }^{39}$ In our study, none of GTRC-treated sites had membrane exposure due to the efforts made to relieve the inherent tissue tension, obtaining primary coverage without any tension.

Increased amounts of KG at 4 and 16 weeks compared to baseline in both treatments might have been due to advancement of flap via coronally positioned flap. Since the mucogingival line has a tendency to regain its genetically defined position, increase of gingival tissue can be advocated by coronally positioned flaps. ${ }^{40}$ Pini Prato et al. ${ }^{41}$ showed more gain of KG in GTR if a longer healing period was allowed. This is supported by the data reported in the literature. $37,40,42$ GTR-based root coverage gained its KG via new tissue regeneration from periodontal ligament cells and mucogingival junction migrated apically overtime.

Limitations of the present study include a small sample size, a short study period, and use of an animal model. Further studies with a longer healing period and a larger sample size are needed. Also, it would be beneficial to use naturally occurring gingival recession defects instead of surgically created ones.

In summary, GTRC produced similar clinical results to those obtained by CAF. The results achieved by GTRC remained constant over time as compared to CAF during this short-term observation interval. Future study is needed to better understand the kinetics of tissue repair using collagen barriers for root coverage.

\section{ACKNOWLEDGMENTS}

The authors acknowledge the expert histologic assistance of Ms. Susan Ryan. This study was supported by The University of Michigan, Periodontal Graduate Student Research Fund. BioMend collagen membranes were donated by Sulzer Dental Inc., Carlsbad, California.

\section{REFERENCES}

1. The American Academy of Periodontology. Glossary of Periodontal Terms, 4th ed. Chicago: The American Academy of Periodontology; 2001:44.

2. Löe H, Anerud A, Boysen H. The natural history of periodontal disease in man: Prevalence, severity, and extent of gingival recession. J Periodontol 1992;63:489-495.

3. Modeer T, Odenrick L. Post-treatment periodontal status of labially erupted maxillary canines. Acta Odontol Scand 1980;38:253-256. 
4. Lindhe J, Socransky SS, Nyman S, Westfelt E. Dimensional alteration of the periodontal tissues following therapy. Int J Periodontics Restorative Dent 1987;7(2):9-22.

5. Grupe J, Warren R. Repair of gingival defects by a sliding flap operation. J Periodontol 1956;27:92-99.

6. Tarnow DP. Semilunar coronally repositioned flap. J Clin Periodontol 1986;13:182-185.

7. Langer B, Langer L. Subepithelial connective tissue graft technique for root coverage. J Periodontol 1985;56:715720.

8. Allen EP, Miller PD Jr. Coronal positioning of existing gingiva: Short term results in the treatment of shallow marginal tissue recession. J Periodontol 1989;60:316319.

9. Caffesse RG, Kon S, Castelli WA, Nasjleti CE. Revascularization following the lateral sliding flap procedure. $J$ Periodontol 1984;55:352-358.

10. Cortellini P, DeSanctis M, Pini Prato G, Baldi C, Clauser C. Guided tissue regeneration procedure using a fibrinfibronectin system in surgically induced recession in dogs. Int J Periodontics Restorative Dent 1991;11:150163.

11. Cortellini P, Clauser C, Pini Prato G. Histologic assessment of new attachment following the treatment of a human buccal recession by means of a guided tissue regeneration procedure. J Periodontol 1993;64:387-391.

12. Tinti C, Vincenzi G, Cortellini P, Pini Prato G, Clauser C. Guided tissue regeneration in the treatment of human facial recession. A 12-case report. J Periodontol 1992;63: 554-560.

13. Vincenzi G, De Chiesa A, Trisi P. Guided tissue regeneration using a resorbable membrane in gingival recession-type defects: A histologic case report in humans. Int J Periodontics Restorative Dent 1998;18:24-33.

14. Wang HL, Bunyaratavej P, Labadie MA, Shyr Y, MacNeil RL. Comparison of two clinical techniques for treatment of gingival recession. J Periodontol 2001;72:1301-1311.

15. Cortellini P, Pini Prato GP, DeSanctis M, Baldi C, Clauser $C$. Guided tissue regeneration procedure in the treatment of a bone dehiscence associated with a gingival recession: A case report. Int J Periodontics Restorative Dent 1991;11:460-467.

16. Roccuzzo $M$, Buser D. Treatment of buccal gingival recessions with e-PTFE membranes and miniscrews: Surgical procedure and results of 12 cases. Int J Periodontics Restorative Dent 1996;16:356-365.

17. Roccuzzo M, Lungo M, Corrente G, Gandolfo S. Comparative study of a bioresorbable and a non-resorbable membrane in the treatment of human buccal gingival recessions. J Periodontol 1996;67:7-14.

18. Shieh AT, Wang HL, O'Neal R, Glickman GN, MacNeil RL. Development and clinical evaluation of a root coverage procedure using a collagen barrier membrane. $J$ Periodontol 1997;68:770-778.

19. Wang HL, O'Neal RB, Thomas CL, Shyr Y, MacNeil RL. Evaluation of an absorbable collagen membrane in treating Class II furcation defects. J Periodontol 1994;65: 1029-1036.

20. Blumenthal NM. A clinical comparison of collagen membranes with e-PTFE membranes in the treatment of human mandibular buccal class II furcation defects. $J$ Periodontol 1993;64:925-333.

21. Sableman E. Biology, Biotechnology and Biocompatibility of Collagen. Biocompatibility of Tissue Analogs. Boca Raton, FL: CRC Press; 1985:27.

22. Johns LP, Merritt K, Agarwal S. Immunogenicity of a bovine collagen membrane in guided tissue regeneration.
J Dent Res 1992;71(Spec. Issue):298(Abstr. 1538).

23. Ozcan G, Kurtis B, Balos K. Combined use of root conditioning, fibrin-fibronectin system and a collagen membrane to treat a localized gingival recession: A 10-case report. J Marmara Univ Dental Faculty 1997;2:588-598.

24. Matter J. Free gingival graft and coronally repositioned flap. A 2-year follow-up report. J Clin Periodontol 1979; 6:437-442.

25. Listgarten MA, Rosenberg MM. Histological study of repair following new attachment procedures in human periodontal lesions. J Periodontol 1979;50:333-344.

26. Guiha R, Khodeiry SE, Mota L, Caffesse RG. Histological evaluation of healing and revascularization of the subepithelial connective tissue graft. J Periodontol 2001; 72:470-478.

27. Pitaru S, Tal H, Soldinger M, Azar AO, Noff M. Collagen membranes prevent the apical migration of epithelium during periodontal wound healing. J Periodont Res 1987; 22:331-333.

28. Weng D, Hurzeler MB, Quinones CR, Pechstadt B, Mota L, Caffesse RG. Healing patterns in recession defects treated with ePTFE membranes and with free connective tissue grafts. A histologic and histometric study in the beagle dog. J Clin Periodontol 1998;25:238-245.

29. Casati MZ, Sallum EA, Caffesse RG, Nociti FH Jr, Sallum AW, Pereira SL. Guided tissue regeneration with a bioabsorbable polylactic acid membrane in gingival recessions. A histometric study in dogs. J Periodontol 2000;71:238-248.

30. Tatakis DN, Trombelli L. Adverse effects associated with a bioabsorbable guided tissue regeneration device in the treatment of human gingival recession defects. A clinicopathologic case report. J Periodontol 1999;70:542547.

31. da Silva Pereira SL, Sallum AW, Casati MZ, Caffesse RG, Nociti FH Jr, Sallum EA. Comparison of bioabsorbable and non-resorbable membranes in the treatment of dehiscence-type defects. A histomorphometric study in dogs. J Periodontol 2000;71:1306-1314.

32. Allen EP, Miller PD. Coronal positioning of existing gingiva/short-term results in the treatment of shallow marginal tissue recession. J Periodontol 1989;60:316-319.

33. Harris RJ, Harris AW. The coronally positioned pedicle graft with inlaid margins: A predictable method of obtaining root coverage of shallow defects. Int $J$ Periodontics Restorative Dent 1994;14:228-241.

34. Harris RJ. A comparative study of root coverage obtained with guided tissue regeneration utilizing a bioabsorbable membrane versus the connective tissue with partial-thickness double pedicle graft. J Periodontol 1997;68:779-790.

35. Chen CC, Wang HL, Smith F, Glickman GN, Shyr Y, O'Neal RB. Evaluation of a collagen membrane with and without bone grafts in treating periodontal intrabony defects. J Periodontol 1995;66:838-847.

36. Pini Prato G, Tinti C, Cortellini P, Magnani C, Clauser C. Periodontal regenerative therapy with coverage of previously restored root surfaces: Case reports. Int $J$ Periodontics Restorative Dent 1992;12:450-461.

37. Borghetti A, Glise JM, Monnet-Corti V, Dejou J. Comparative clinical study of a bioabsorbable membrane and subepithelial connective tissue graft in the treatment of human gingival recession. J Periodontol 1999;70:123130.

38. Trombelli L, Schincaglia G, Checchi L, Calura G. Combined guided tissue regeneration, root conditioning, and fibrin-fibronectin system application in the treatment of 
gingival recession. A 15-case report. J Periodontol 1994; 65:796-803.

39. Jepsen K, Heinz B, Halben JH, Jepsen S. Treatment of gingival recession with titanium reinforced barrier membranes versus connective tissue grafts. J Periodontol 1998;69:383-391.

40. Zucchelli G, Clauser C, De Sanctis M, Calandriello M. Mucogingival versus guided tissue regeneration procedures in the treatment of deep recession type defects. $J$ Periodontol 1998;69:138-145.

41. Pini Prato G, Clauser C, Cortellini P, Tinti C, Vincenzi G, Pagliaro U. Guided tissue regeneration versus mucogingival surgery in the treatment of human buccal recessions. A 4-year follow-up study. J Periodontol 1996;67: 1216-1223.

42. Harris RJ. A comparison of 2 root coverage techniques: Guided tissue regeneration with a bioabsorbable matrix style membrane versus a connective tissue graft combined with a coronally positioned pedicle graft without vertical incisions. Results of a series of consecutive cases. J Periodontol 1998;69:1426-1434.
Correspondence: Dr. Hom-Lay Wang, Department of Periodontics/Prevention/Geriatrics, The University of Michigan, School of Dentistry, 1011 North University Avenue, Ann Arbor, MI 48109-1078. Fax: 734/936-0374; e-mail: homlay@umich.edu.

Accepted for publication February 15, 2002. 